\title{
Numerical simulations of residual stress and inhomogeneous conductivity effects in CNT-filled resins cured by electric field
}

\author{
R. Matsuzaki*, S. Hatori \\ Department of Mechanical Engineering, Tokyo University of Science, 2641 Yamazaki, Noda, Chiba 278-8510, Japan
}

Received 28 May 2015; accepted in revised form 10 August 2015

\begin{abstract}
To achieve uniform curing of resin, internal heating with the addition of carbon nanotubes (CNTs) has attracted considerable attention. Numerical simulations of the residual stress in CNT-filled resins cured by an electric field were carried out in the present study, taking into account the CNT dispersion within the resins. The simulations were based on an unsteady-heat-transfer equation and the cure reaction; the residual stress due to the thermal expansion and cure shrinkage was calculated using a finite element method. In addition, microscope images of actual CNT-filled resins were used for modeling the inhomogeneous electrical conductivity due to CNT aggregates. The simulation results show that, compared to external heating, Joule heating, or resistive heating, in which a conductive material itself generates heat from the passage of an electric current, enables more uniform curing and generally suppresses the residual stress. However, high local residual stress was observed around the high-electrical conductivity region in the model with inhomogeneous electrical conductivity. The present results thus highlight the need to take into account the inhomogeneity of CNT-filled resins for accurate evaluation of the residual stress.
\end{abstract}

Keywords: polymer composites, nanocomposites, mechanical properties, modeling and simulation, carbon nanotubes

\section{Introduction}

External heating, such as that in the autoclave curing of thermosetting composites, may induce inhomogeneities in the temperature distribution or in the progression of curing because the temperature of the material's surface is raised by convective heat transfer from the atmosphere. The inhomogeneity of the curing process is especially evident in complex or thick composite structures, where residual stress and strain are induced, and the inhomogeneity may eventually initiate defects such as matrix cracks and deterioration of properties [1-3]. In order to achieve more uniform curing of the thermosetting resin, internal heating via an electric field has attracted considerable attention because it allows the material to be heated from the inside. Compared with conventional external heating, it has been reported that inter- nal heating leads to improved mechanical properties [4-7], adhesive bonding [8], and heating efficiency, as well as shorter curing cycles [9-11].

It is possible to increase the amount of heat generated by internal heating, such as microwave or Joule heating, by adding conductive fillers like carbon nanotubes (CNTs) [12-14] or carbon black [15] to the uncured thermosetting resin. At the same time, the inclusion of nanofillers leads to superior mechanical, conductive [16-18], and dielectric [19] properties compared with neat resins [20-23]. However, conventional microwave-heating equipment is very expensive, especially for curing large-scale structures, thus offsetting the advantages of improved energy efficiency. In addition, because the composite structures need to be enclosed within the conventional microwave-heating equipment, the struc-

\footnotetext{
${ }^{*}$ Corresponding author, e-mail: rmatsuza@rs.tus.ac.jp

(C) BME-PT
} 
tures must be smaller than the equipment's heating chamber. The expensive production costs and the limit on the size of molded composites represent serious problems for the application of the composites in consumer products such as automobiles. This highlights the need to develop new methods for uniform heating and curing that do not require expensive tools and accessories.

To meet this demand, we had developed in earlier studies a microwave curing method using thin-filmtype electrode arrays and CNTs added to the epoxy resin, as shown in Figure 1a [24-27]. The method yields a heating efficiency as high as $70 \%$ and a drastic increase in the amount of heat generated when the added CNT content reaches the percolation threshold [28]. However, in microwave-based curing processes, because an inhomogeneous electrical conductivity (such as in the presence of CNT aggregates) may induce localized heat generation (Figure 1b) [28-31], it is clear that the distribution of CNTs must be taken into account for an accurate evaluation of the residual stress. Whereas numerical simulations can be used to assess the effect of an inhomogeneous CNT distribution on residual stress, simulations of this kind have yet to be conducted.
Therefore, in the present study, we performed numerical simulations to investigate how an inhomogeneous CNT distribution affects CNT-filled thermosetting resins cured via an electric field. The inhomogeneous electrical conductivity was modeled using the microscope images of actual CNT aggregates, and the simulations were based on the analysis of unsteady heat transfer, including Joule heating and heat generated by the curing reaction. The residual stress due to the thermal expansion and cure shrinkage was calculated using the finite element method based on linear viscoelastic models. We compared the residual stress induced by internal (electric field) and external (heat flux) heating. Finally, we compared homogeneous and inhomogeneous conductivity models to investigate the effect of the conductivity distribution of a CNT-filled resin on the residual stress.

\section{Materials and methods}

\subsection{Inhomogeneous conductivity and heat transfer models}

\subsubsection{Inhomogeneous conductivity model of CNT-filled resin}

Because it is difficult to attain uniform dispersion without the formation of CNT aggregates, the CNT

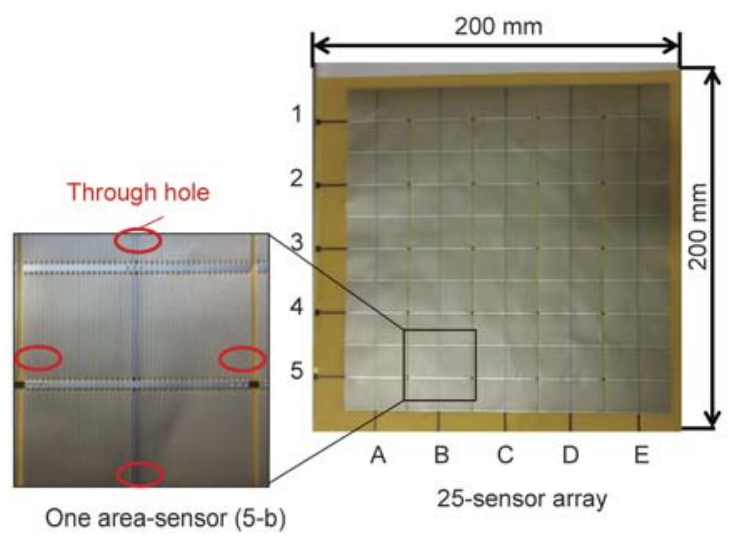

Schematic

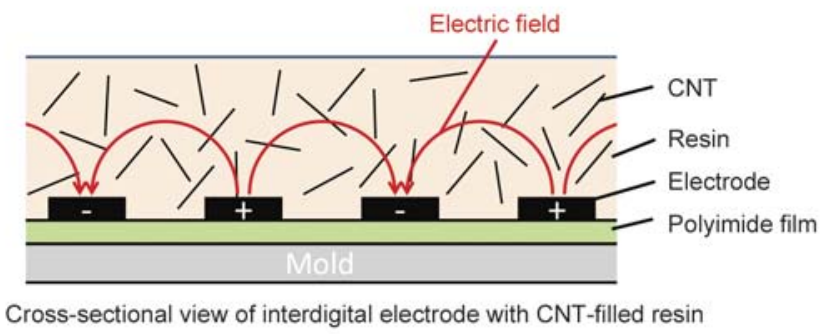

a)

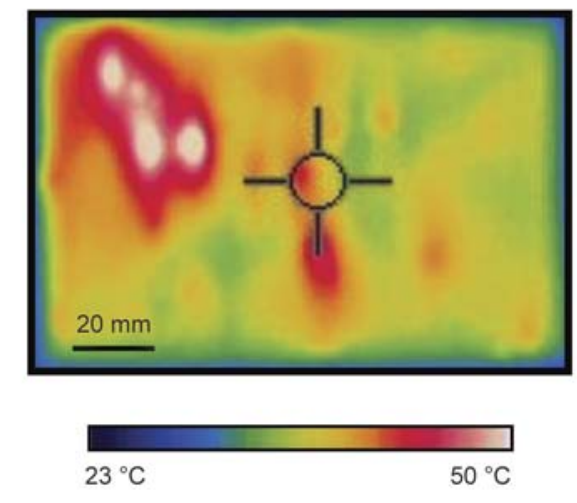

b)

Figure 1. Microwave curing using thin-film-type electrode arrays and CNTs added to the epoxy resin. (a) Schematic of multifunctional interdigital electrode array (MIEA) film and cross-sectional view of interdigital electrode with CNT-filled resin. (b) Localized heat generation inside an interdigital electrode with CNT-filled resin. 
distribution should be taken into account when modeling the electrical conductivity. In order to model the electrical conductivity of the CNT-filled resin, we used optical microscope images of 0.05 $1.0 \mathrm{wt} \%$ CNT-filled resins (Figure 2a). For preparation of CNT-filled resin, the CNTs (VGCF-X, Showa Denko, $3 \mu \mathrm{m}$ in length, and $15 \mathrm{~nm}$ in diameter) were dried in an oven at $100^{\circ} \mathrm{C}$ for $1 \mathrm{~h}$, after which they were mixed with unsaturated polyester (PC-184-C, Sundhoma) in a planetary kneader machine (NBK-1, Nissei) at $1700 \mathrm{rpm}$ for $3 \mathrm{~min}$. The sample mixtures were thereafter treated in an ultrasonic bath sonicator (US-2K, AS ONE) for $2 \mathrm{~h}$, with further mixing of $3 \mathrm{~min}$ in the kneader machine every $30 \mathrm{~min}$. The image of each CNT-filled resin was binarized (i.e., converted into a black and white image), and the CNT area ratio VCNT was calculated by assuming that the CNTs are displayed as dark areas in the images. By using the electrical conductivity measured for each CNT weight percentage shown in Figure 3a [32], we obtained the relationship between the microscopic electrical conductivity and CNT area ratio $V_{\mathrm{CNT}}$, shown in Figure $3 \mathrm{~b}$. In order to model the electrical conductivity distribution of a macroscopic region, the corresponding CNT distribution image was obtained and binarized; examples of the model and binarized image of the $0.2 \mathrm{wt} \%$ CNTfilled resin are shown in Figure $2 b$ and $2 c$. The binarized image was discretized into small regions, whose corresponding $V_{\mathrm{CNT}}$ was calculated (Figure $2 \mathrm{~d}$ ); the electrical conductivity of each microscopic region was then allocated (Figure 2e) based on the relationship between $V_{\mathrm{CNT}}$ and the electrical conductivity revealed in Figure 3b. The size of the microscopic region was determined to match the mesh size of the numerical analysis, which is $0.1 \mathrm{~mm} \times 0.1 \mathrm{~mm}$ in the present study. It should be noted that the depiction in Figure $2 \mathrm{~d}$ was generated by interpolating the $0.1 \mathrm{~mm} \times 0.1 \mathrm{~mm}$ mesh value in Figure $2 \mathrm{c}$. Figure $2 \mathrm{e}$ was also generated by interpolating the measured values in Figure 3b. The validity of this approach was confirmed by the agreement between the macroscopic electrical conductivity obtained from the inhomogeneous conductivity model and the conductivity measured for the resin with the same added CNT content.

\subsubsection{Unsteady-heat-transfer equation}

The unsteady-heat-transfer equation for the heat generated by the resin cure reaction and by Joule heating under an electric field is given by Equation (1):

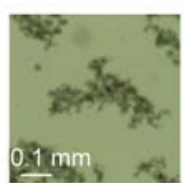

0.05 wt $\%$

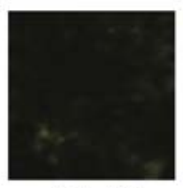

$0.5 w t \%$

a)

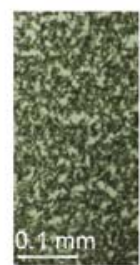

b)

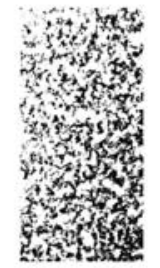

c)

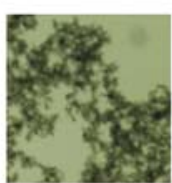

$0.1 w t \%$

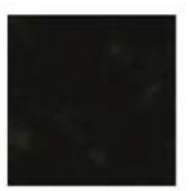

$1.0 w t \%$

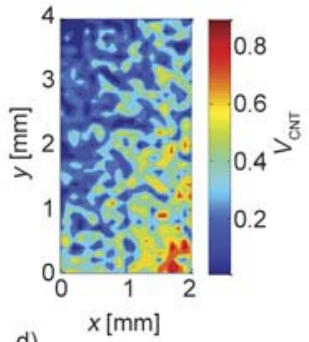

d)

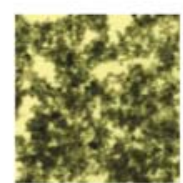

$0.2 w t \%$

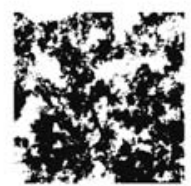

Binarized image $(0.2 \mathrm{wt} \%)$

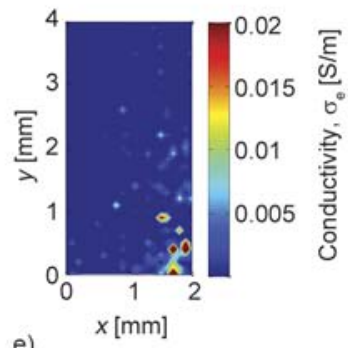

e)

Figure 2. Modeling of inhomogeneous electrical conductivity of CNT-filled resins. (a) Microscope image of CNT-filled resins with various CNT concentrations [wt\%] and binarized image of $0.2 \mathrm{wt} \%$ CNT-filled resin. (b) Analytical model of $0.2 \mathrm{wt} \%$ CNT-filled resin. (c) Binarized image of (b). (d) Distribution of CNT area ratio (VCNT). (e) Distribution of electrical conductivity $\left(\sigma_{\mathrm{e}}\right)$. 


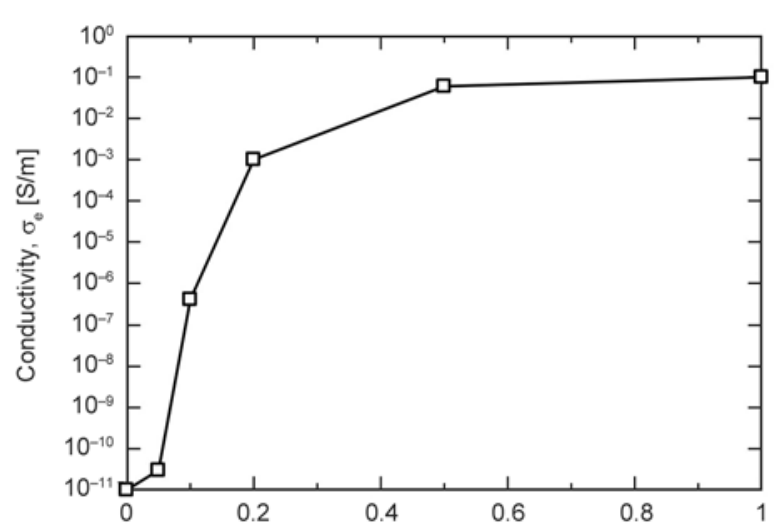

a)

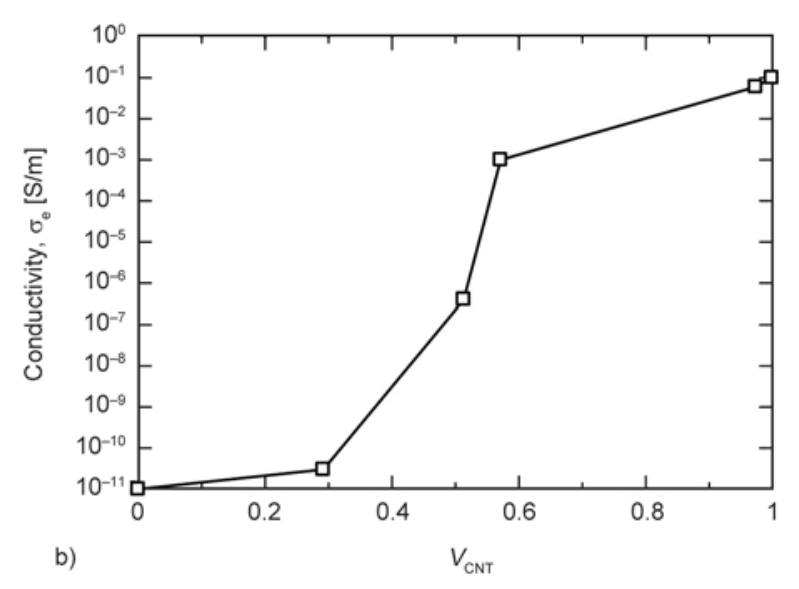

Figure 3. CNT content, electric conductivity $\sigma_{\mathrm{e}}$, and CNT area ratio $V_{\mathrm{CNT}}$ of CNT-filled resins. (a) Relationship between electrical conductivity and CNT content [32]. (b) Relationship between electrical conductivity and $V_{\mathrm{CNT}}$.

$\rho c \frac{\partial T}{\partial t}=\frac{\partial}{\partial x}\left(k_{\mathrm{xx}} \frac{\partial T}{\partial x}\right)+\frac{\partial}{\partial y}\left(k_{\mathrm{yy}} \frac{\partial T}{\partial y}\right)+\dot{Q}_{\mathrm{j}}+\rho \dot{Q}_{\mathrm{c}}$

where $T$ is the temperature, $\rho$ is the density, $c$ is the specific heat, $\dot{Q}_{\mathrm{j}}$ is the heat generation rate per unit volume due to Joule heating, and $\dot{Q}_{\mathrm{c}}$ is the heat generation rate per unit weight due to the curing reaction; $k_{\mathrm{xx}}$ and $k_{\mathrm{yy}}$ are the coefficients of thermal conductivity in the $\mathrm{x}$ and $\mathrm{y}$ direction, respectively.

The heat generation rate due to Joule heating $\dot{Q}_{\mathrm{j}}$ under an electric field $\mathbf{E}$ is given by Equation (2):

$\dot{Q}_{\mathrm{j}}=\mathbf{J} \cdot \mathbf{E}=\left(\sigma_{\mathrm{e}} \mathbf{E}\right) \cdot \mathbf{E}=\sigma_{\mathrm{e}}\|\nabla V\|$

where $\mathbf{J}$ is the electric current density, $\sigma_{\mathrm{e}}$ is the electrical conductivity, and $V$ is the applied voltage. The heat generation rate due to the cure reaction $\dot{Q}_{\mathrm{c}}$ is given by the following Equation (3), using a cure reaction model for unsaturated polyester resins [33]:

$\dot{Q}_{\mathrm{c}}=H_{\mathrm{r}} \frac{\mathrm{d} \alpha}{\mathrm{d} t}=H_{\mathrm{r}} k_{\mathrm{l}} \exp \left(-\frac{E_{\mathrm{a}}}{R T}\right)(\alpha)^{\mathrm{m}}(1-\alpha)^{\mathrm{n}}$

where $\alpha$ is the degree of cure, $k_{1}$ is the reaction rate constant, $E_{\mathrm{a}}$ is the activation energy, $R$ is the gas constant, $m$ and $n$ are reaction orders, and $H_{\mathrm{r}}$ is the total heat of reaction.

\subsection{Analysis of residual stress and strain}

\subsubsection{Strain induced by thermal expansion and cure shrinkage}

The rate of change in volumetric strain of the resin induced by thermal expansion and cure shrinkage is given by Equation (4) [34]:

$$
\left(\frac{1}{V_{0}} \frac{\mathrm{d} V}{\mathrm{~d} t}\right)=\left(\frac{1}{V_{0}} \frac{\mathrm{d} V}{\mathrm{~d} t}\right)_{\text {thermal }}-\left(\frac{1}{V_{0}} \frac{\mathrm{d} V}{\mathrm{~d} t}\right)_{\text {polymerization }}
$$

where $V_{0}$ is the initial volume, the first term of the right-hand side represents the contribution of bulk thermal expansion and contraction, and the second term is the volumetric strain change due to the cure shrinkage. These two terms are given by Equations (5) and (6):

$$
\left(\frac{1}{V_{0}} \frac{\mathrm{d} V}{\mathrm{~d} t}\right)_{\text {thermal }}=\left\{\beta_{\mathrm{gel}}(T)(1-\alpha)+\beta_{\text {cured }}(T) \alpha\right\} \frac{\mathrm{d} T}{\mathrm{~d} t}
$$

$$
\left(\frac{1}{V_{0}} \frac{\mathrm{d} V}{\mathrm{~d} t}\right)_{\text {polymerization }}=\lambda_{\text {chem }} \frac{\mathrm{d} \alpha}{\mathrm{d} t}
$$

where $\beta_{\text {gel }}$ and $\beta_{\text {cured }}$ are the coefficients of thermal expansion of the uncured and fully cured resin, respectively, and $\lambda_{\text {chem }}$ is the total polymerization shrinkage. The coefficients $\beta_{\text {gel }}$ and $\beta_{\text {cured }}$ are functions of the temperature $T$ and are given by Equation (7):

$\beta_{\text {gel }}=e_{1} T+f_{1} ; \beta_{\text {cured }}=e_{2} T+f_{2}$

where $e_{1}, f_{1}, e_{2}$, and $f_{2}$ are material-dependent parameters.

\subsubsection{Viscoelastic model taking into account temperature and degree of cure}

To model the material behavior when changing from a liquid to a solid state during the curing process, the mechanical behavior of the polymer resins is 
expressed by the following linear viscoelastic constitutive Equation (8):

$\sigma(t)=\int_{0}^{\mathrm{t}} E\left(\xi(t)-\xi^{\prime}(\tau)\right) \frac{\mathrm{d} \varepsilon}{\mathrm{d} \tau} \mathrm{d} \tau$

where $\sigma$ is the relaxation stress, $E$ is the relaxation modulus, and $\varepsilon$ is the strain. $\xi$ and $\xi^{\prime}$ are reduced time variables that depend on temperature and the degree of cure (see also Equation (12)). For the relaxation modulus, we used the following generalized Maxwell model (Equation (9)) that takes into account the temperature and degree of cure [35]:

$E(\xi, \alpha)=E_{\infty}+\left(E_{\mathrm{u}}-E_{\infty}\right) \sum_{\mathrm{i}=1}^{\mathrm{n}} W_{\mathrm{i}} \exp \left(\frac{-\xi(\alpha, T)}{\tau_{\mathrm{i}}(\alpha)}\right)$

where $E_{\infty}$ is the fully relaxed modulus, $E_{\mathrm{u}}$ is the unrelaxed modulus, $W_{\mathrm{i}}$ is the weight factor for the $i^{\text {th }}$ element, and $\tau_{\mathrm{i}}$ is the discrete stress relaxation time of each element. $\tau_{\mathrm{i}}$ depends on the degree of cure and is expressed by Equations (10) and (11):

$$
\begin{aligned}
\log \left(\tau_{\mathrm{i}}(\alpha)\right) & =\log \left(\tau_{\mathrm{i}}\left(\alpha_{\text {ref }}\right)\right)+f^{\prime}(\alpha)- \\
& -\left(\alpha-\alpha_{\text {ref }}\right) \log \left(\frac{\tau_{\mathrm{p}}\left(\alpha_{\text {ref }}\right)}{\tau_{\mathrm{i}}\left(\alpha_{\text {ref }}\right)}\right)
\end{aligned}
$$

$f^{\prime}(\alpha)=0.0536+0.0615 \alpha+0.9227 \alpha^{2}-1$

where $\alpha_{\text {ref }}$ is the reference degree of cure $(=0.98)$, and $\tau_{\mathrm{p}}$ is the maximum stress relaxation time at the reference degree of cure. The reduced times are given by Equation (12):

$\xi=\int_{0}^{\mathrm{t}} \frac{1}{a_{\mathrm{T}}} \mathrm{d} t, \xi^{\prime}=\int_{0}^{\tau} \frac{1}{a_{\mathrm{T}}} \mathrm{d} t$,

$\log a_{\mathrm{T}}=\left(-a_{1} \exp \left(\frac{1}{\alpha-1}\right)-a_{2}\right)\left(T-T_{\mathrm{ref}}\right)$

where $a_{\mathrm{T}}$ is the shift factor, $T_{\text {ref }}\left(=30^{\circ} \mathrm{C}\right)$ is the reference temperature, and $a_{1}$ and $a_{2}$ are materialdependent parameters.

\subsubsection{Residual stress analysis using finite element method}

The residual stress is calculated using the finite element method on the basis of the principle of virtual work (see Equation (13)):

$$
\int_{\mathrm{V}}(\delta \boldsymbol{\varepsilon})^{\mathrm{T}} \boldsymbol{\sigma}_{\text {res }} \mathrm{d} V=\int_{\mathrm{V}}(\delta \mathbf{u})^{\mathrm{T}} \mathbf{b} \mathrm{d} V+\int_{\mathrm{V}}(\delta \mathbf{u}) \mathbf{t} \mathrm{d} S
$$

where $\boldsymbol{\varepsilon}$ is the total strain vector, $\mathbf{u}$ is the displacement vector, $\mathbf{b}$ is the body force vector per unit volume, $\mathbf{t}$ is the surface force vector per unit area, and $S$ is the mechanical boundary $\left[\mathrm{m}^{2}\right]$.

Let us consider the unknown state at the time $t=$ $t+\Delta t$, where the state at the time $t$ is known. Equation (13) can then be linearized as shown by Equation (14):

$$
\begin{aligned}
\Delta t \int_{\mathrm{V}_{\mathrm{t}}}(\delta \boldsymbol{\varepsilon})^{\mathrm{T}} \dot{\boldsymbol{\sigma}}_{\mathrm{res}} \mathrm{d} V & =\int_{\mathrm{V}_{\mathrm{t}^{\prime}}}(\delta \mathbf{u})^{\mathrm{T}} \mathbf{b} \mathrm{d} V+\int_{\mathrm{S}_{\mathrm{t}^{\prime}}}(\delta \mathbf{u}) \mathbf{t} \mathrm{d} S- \\
& -\int_{\mathrm{V}_{\mathbf{t}}}(\delta \boldsymbol{\varepsilon})^{\mathrm{T}} \boldsymbol{\sigma}_{\mathrm{res}} \mathrm{d} V
\end{aligned}
$$

where the subscripts $t$ and $t^{\prime}$ for $V$ and $S$ represent the system states at times $t$ and $t^{\prime}$, respectively. The total strain rate vector $\dot{\boldsymbol{\varepsilon}}$ is composed of the residual strain rate vector $\dot{\boldsymbol{\varepsilon}}_{\text {res }}$ and the initial strain rate vector $\dot{\boldsymbol{\varepsilon}}_{0}$, which can be expressed in terms of the volumetric strain change (see Equation (15)):

$\dot{\boldsymbol{\varepsilon}}=\dot{\boldsymbol{\varepsilon}}_{\mathrm{res}}+\dot{\boldsymbol{\varepsilon}}_{0}=\dot{\boldsymbol{\varepsilon}}_{\mathrm{res}}+\left\{\frac{1}{3 V_{0}} \frac{\mathrm{d} V}{\mathrm{~d} t} \frac{1}{3 V_{0}} \frac{\mathrm{d} V}{\mathrm{~d} t} 0\right\}^{\mathrm{T}}$

$\dot{\boldsymbol{\sigma}}_{\text {res }}$ is given as follows, using the stress-strain and strain-displacement matrices $\mathbf{D}$ and $\mathbf{B}$, respectively, as described by Equation (16):

$\dot{\boldsymbol{\sigma}}_{\text {res }}=\mathbf{D} \dot{\boldsymbol{\varepsilon}}_{\text {res }}=\mathbf{D}\left(\dot{\boldsymbol{\varepsilon}}-\dot{\boldsymbol{\varepsilon}}_{0}\right)=\mathbf{D}\left(\mathbf{B} \dot{\mathbf{d}}_{\mathrm{e}}-\dot{\boldsymbol{\varepsilon}}_{0}\right)$

where $\dot{\mathbf{d}}_{\mathrm{e}}$ represents the nodal displacement vector in an element. Here, $\mathbf{D}$ is composed of the relaxation modulus $E$ and Poisson's ratio $v$. It should be noted that the Poisson's ratio is constant and does not depend on the degree of cure [2]. By substituting Equation (16) into Equation (14), the following Equation (17) can be obtained:

$$
\begin{array}{r}
\int_{\mathrm{V}_{\mathrm{t}}}(\delta \boldsymbol{\varepsilon})^{\mathrm{T}} \mathbf{D}\left(\Delta \boldsymbol{\varepsilon}-\Delta \boldsymbol{\varepsilon}_{0}\right) \mathrm{d} V=\int_{\mathrm{V}_{\mathrm{t}^{\prime}}}(\delta \mathbf{u})^{\mathrm{T}} \mathbf{b} \mathrm{d} V+ \\
+\int_{\mathrm{S}_{\mathrm{t}^{\prime}}}(\delta \mathbf{u}) \mathbf{t} \mathrm{d} S-\int_{\mathrm{V}_{\mathrm{t}}}(\delta \boldsymbol{\varepsilon})^{\mathrm{T}} \boldsymbol{\sigma}_{\text {res }} \mathrm{d} V
\end{array}
$$

Using the total nodal displacement vector $\Delta \mathbf{d}$ and $\mathbf{B}$ when the body and surface forces are zero, Equation (17) can be rewritten as shown by Equation (18):

$$
\begin{aligned}
& \left(\sum_{\text {elements }} \int_{\mathrm{V}_{\mathrm{t}}} \mathbf{B}^{\mathrm{T}} \mathbf{D} \mathbf{B} \mathrm{d} V\right) \Delta \mathbf{d}= \\
& =\sum_{\text {elements }} \int_{\mathrm{V}_{\mathrm{t}}} \mathbf{B}^{\mathrm{T}} \mathbf{D} \Delta \boldsymbol{\varepsilon}_{0} \mathrm{~d} V-\sum_{\text {elements }} \int_{\mathrm{V}_{\mathrm{t}}} \mathbf{B}^{\mathrm{T}} \boldsymbol{\sigma}_{\text {res }} \mathrm{d} V
\end{aligned}
$$


By solving the system of linear equations in Equation (18), we can obtain the total nodal displacement vector $\Delta \mathbf{d}$; thereby, the residual stress $\dot{\boldsymbol{\sigma}}_{\text {res }}$ can be calculated from Equation (16).

\subsection{Simulation of residual stress}

\subsubsection{Analytical conditions}

We investigated the effect of the curing process on the residual stress by modeling the interdigital electrodes, as shown in Figure 4a. We compared models of external heating by heat flux and internal heating by an electric field, schematically illustrated in Figures $4 \mathrm{~b}$ and $4 \mathrm{c}$, respectively. In the models, the heat transfer coefficient $\mathrm{h}$ between the resin at the top of the model and the atmosphere was $10 \mathrm{~W} /\left(\mathrm{m}^{2} \cdot \mathrm{K}\right)$, and the initial temperatures of the resin $\left(T_{0}\right)$ and atmosphere $\left(T_{\mathrm{w}}\right)$ was $25^{\circ} \mathrm{C}$. The electrical conductivity distribution of the $0.2 \mathrm{wt} \%$ CNT-loaded resin shown in Figure 2e was used for the inhomogeneous electrical conductivity model, while a constant electric conductivity $\sigma_{\mathrm{e}}=10^{-3} \mathrm{~S} / \mathrm{m}$ was employed in the homogeneous model, corresponding to the average electrical conductivity of the $0.2 \mathrm{wt} \% \mathrm{CNT}$ loaded resin. The applied voltage $V$ was set to a value such that the minimum degree of cure in the model reached 0.95 after $1600 \mathrm{~s}$ from the start of the analysis. The applied voltages and heat flux values for heating the CNT-filled resin are summarized in Table 1 . The residual stress was analyzed by the finite element method using four-node quadrilateral elements, assuming a plane-strain state. To establish the boundary conditions, the $y$ directional displacement was constrained to the bottom line; an $x$ directional displacement constraint was also added at the middle point of the bottom line to keep the model fixed. The material properties are shown in Tables 2 and 3 [33-36]. In addition, we investigated more rapid and uniform curing cases: the interdigital elec-
Table 1. Values of applied voltage and heat flux for heating the CNT-filled resin from the bottom of the model

\begin{tabular}{|l|r|}
\hline Heat flux $q\left[\mathrm{~J} /\left(\mathrm{m}^{2} \cdot \mathrm{s}\right)\right]$ & 753.2 \\
\hline Applied voltage (homogeneous model) [V] & 72.1 \\
\hline Applied voltage (inhomogeneous model) [V] & 42.8 \\
\hline
\end{tabular}

Table 2. Material properties and parameters of cure kinetics and volumetric change for the thermosetting resin (Equations (1)-(7)) [33, 34, 36]

\begin{tabular}{|cl|c|}
\hline$\rho$ & {$\left[\mathrm{kg} / \mathrm{m}^{3}\right]$} & 1094.9 \\
\hline$K$ & {$[\mathrm{~W} /(\mathrm{m} \cdot \mathrm{K})]$} & 0.14 \\
\hline$c$ & {$[\mathrm{~J} /(\mathrm{mol} \cdot \mathrm{kg})]$} & 1630 \\
\hline$k_{1}$ & {$[1 / \mathrm{K}]$} & $6.167 \cdot 10^{20}$ \\
\hline$E_{\mathrm{a}}$ & {$[\mathrm{J} / \mathrm{mol}]$} & $1.674 \cdot 10^{5}$ \\
\hline$m$ & & 0.524 \\
\hline$n$ & & 1.476 \\
\hline$R$ & {$[\mathrm{~J} /(\mathrm{mol} \cdot \mathrm{K})]$} & 8.314 \\
\hline$H_{\mathrm{r}}$ & {$[\mathrm{J} / \mathrm{kg}]$} & $7.750 \cdot 10^{4}$ \\
\hline$e_{1}$ & {$[\mathrm{~J} /(\mathrm{mol} \cdot \mathrm{K})]$} & $9.167 \cdot 10^{-7}$ \\
\hline$e_{2}$ & {$[\mathrm{~J} /(\mathrm{mol} \cdot \mathrm{K})]$} & $9.167 \cdot 10^{-3}$ \\
\hline$f_{1}$ & {$[\mathrm{~J} / \mathrm{kg}]$} & $2.425 \cdot 10^{5}$ \\
\hline$f_{2}$ & {$[\mathrm{~J} / \mathrm{kg}]$} & $5.250 \cdot 10^{-5}$ \\
\hline$\lambda_{\text {chem }}$ & & 0.07 \\
\hline
\end{tabular}

Table 3. Constants of the viscoelastic model for $\alpha_{\text {ref }}=0.98$ (Equations (8)-(12)) [35]

\begin{tabular}{|c|c|c|}
\hline $\boldsymbol{i}$ & $\begin{array}{c}\boldsymbol{\tau}_{\mathbf{i}} \\
{[\mathbf{m i n}]}\end{array}$ & $\boldsymbol{W}_{\mathbf{i}}$ \\
\hline 1 & $2.92 \cdot 10^{1}$ & 0.059 \\
2 & $2.92 \cdot 10^{3}$ & 0.066 \\
3 & $1.82 \cdot 10^{5}$ & 0.083 \\
4 & $1.10 \cdot 10^{7}$ & 0.112 \\
5 & $2.83 \cdot 10^{8}$ & 0.154 \\
6 & $7.94 \cdot 10^{9}\left(\tau_{\mathrm{p}}\right)$ & 0.262 \\
7 & $1.95 \cdot 10^{11}$ & 0.184 \\
8 & $3.32 \cdot 10^{12}$ & 0.049 \\
9 & $4.92 \cdot 10^{14}$ & 0.025 \\
\hline$E_{\infty}[\mathrm{GPa}]$ & 0.031 & \\
$E_{\mathrm{u}}[\mathrm{GPa}]$ & 0.32 & \\
$a_{1}[1 / \mathrm{K}]$ & 1.4 & \\
$a_{2}[1 / \mathrm{K}]$ & 0.0712 & \\
\hline
\end{tabular}

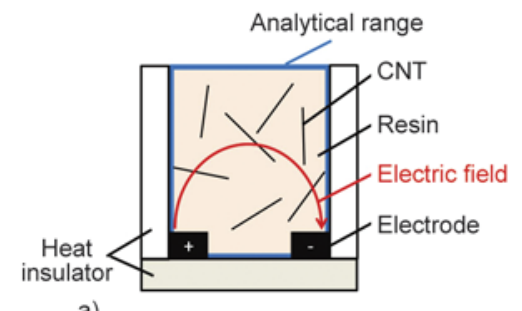

a)

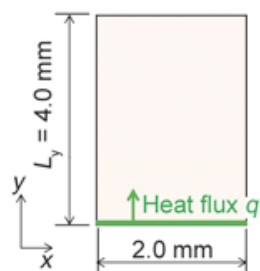

b)

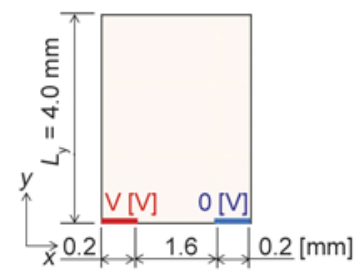

c)

Figure 4. Analytical models and applied voltage conditions using electrodes and heat flux for heating the CNT-filled resins for single-sided heating. (a) Schematic cross-sectional view of the analytical model by (b) heat flux and (c) electric field using electrodes. 


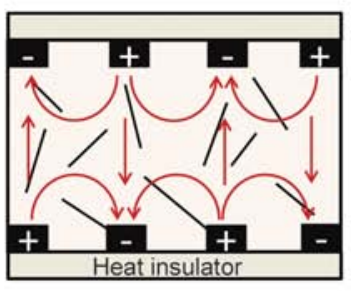

a)

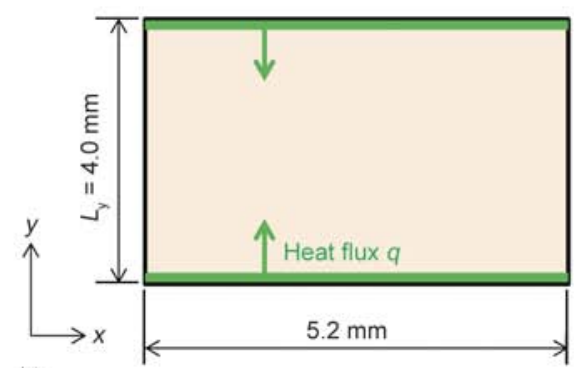

b)

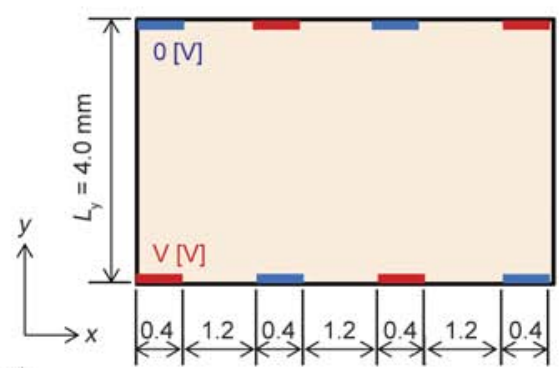

c)

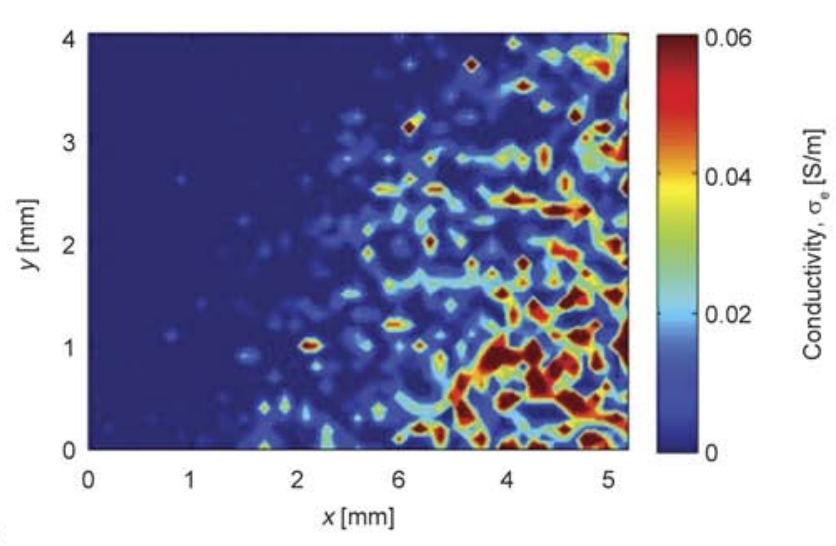

d)

Figure 5. Analytical models and applied voltage conditions using electrodes and heat flux for heating the CNT-filled resins for double-sided heating. (a) Cross-sectional view of analytical model by (b) heat flux and (c) electric field using electrodes. (d) Inhomogeneous electrical conductivity oe for the double-sided heating model.

Table 4. Values of applied voltage and heat flux for heating the CNT-filled resin from both sides

\begin{tabular}{|l|c|}
\hline Heat flux $q\left[\mathrm{~J} /\left(\mathrm{m}^{2} \cdot \mathrm{s}\right)\right]$ & 561.7 \\
\hline Applied voltage (homogeneous model) $[\mathrm{V}]$ & 53.1 \\
\hline Applied voltage (inhomogeneous model) $[\mathrm{V}]$ & 17.1 \\
\hline
\end{tabular}

trode films were placed on the upper and lower surfaces of the mold, and the electric field was applied to the CNT-filled resin between the mold plates, as shown in Figure $5 a$. Figure $5 b$ and $5 c$ show schemes of heat-flux and electric-field heating, respectively; the heat flux and electric field parameters are summarized in Table 4. Homogeneous $\left(\sigma_{\mathrm{e}}=10^{-3} \mathrm{~S} / \mathrm{m}\right)$ and inhomogeneous models (Figure $5 \mathrm{~d}$ ) of the electrical conductivity of the CNT-filled resin were also obtained.

\section{Results and discussion}

Figure 6 shows the distributions of residual stress in the $x$ and $y$ directions after $3600 \mathrm{~s}$ of heating by heat flux and an electric field in both homogeneous and inhomogeneous models. The results show that the residual stress is suppressed in the case of electricfield heating, compared with the case of heat-flux heating. The different residual stress distributions are attributed to the non-uniform curing process
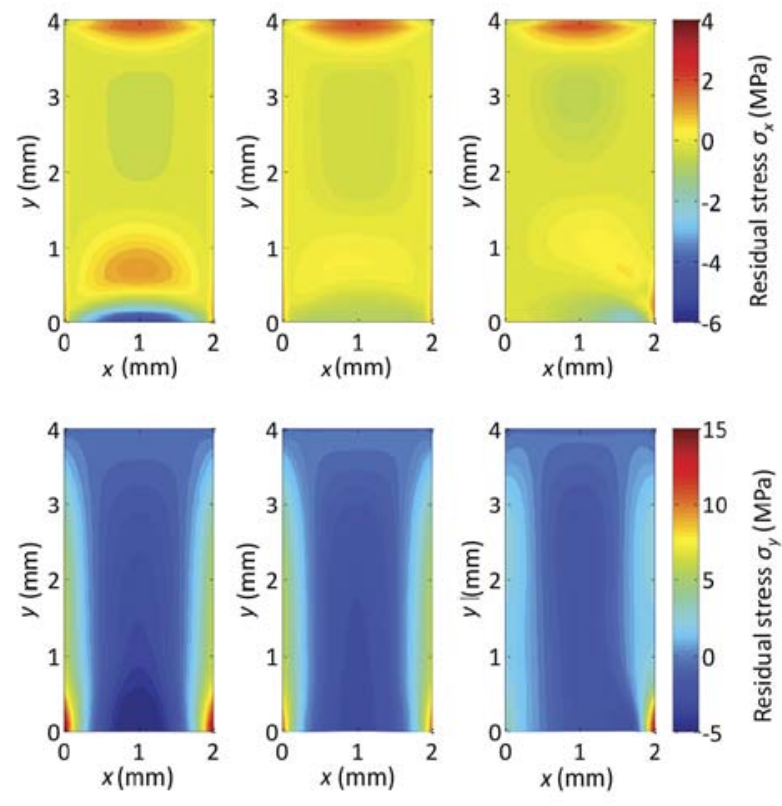

Heat flux

Electric field (homogeneous)

Electric field

(inhomogeneous)

Figure 6. Cross-sectional contour plots of residual stresses $\sigma_{\mathrm{x}}$ and $\sigma \mathrm{y}$ of CNT-filled resin heated from the bottom of the mold. After $3600 \mathrm{~s}$ of heating by heat flux and electric field.

along the thickness direction. Figure 7 shows the difference between the maximum and minimum degree of cure $\left(\alpha_{\mathrm{y}=0}-\alpha_{\mathrm{y}=4}\right)$ at $x=1.0 \mathrm{~mm}$. Around 


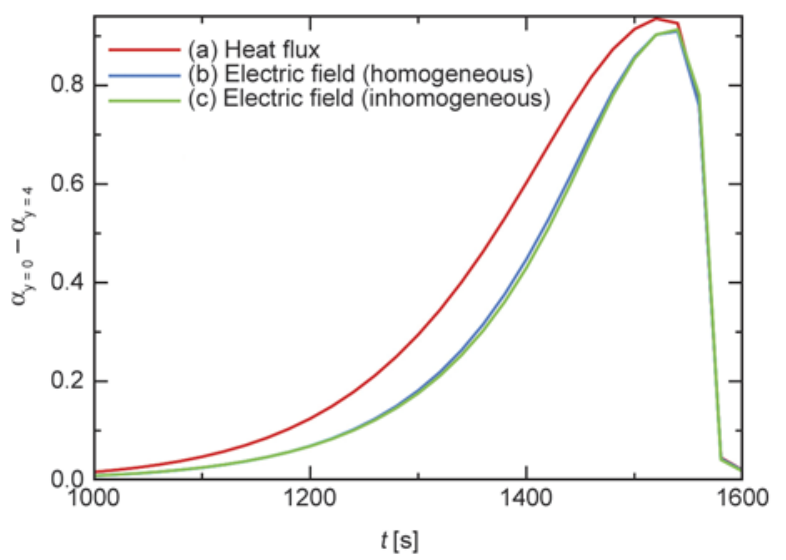

Figure 7. Difference between maximum and minimum degree of cure $\left(\alpha_{\max }\right.$ and $\left.\alpha_{\min }\right)$ at $x=1.0 \mathrm{~mm}$ of CNT-filled resin heated from the bottom of the mold

$1000-1600 \mathrm{~s}$, the difference in the degree of cure for electric-field heating (homogeneous and inhomogeneous) case is smaller than the difference observed for heat-flux heating. This happens because upon application of the electric field, the Joule heating generates heat inside the model; thus, heating and curing can progress uniformly along the thickness direction. In the present analytical model, residual stress occurs because the part that is already cured constrains the cure shrinkage of the portion whose curing is still in progress. Therefore, the uniform curing progress achieved by applying the electric field successfully prevents the development of residual stress. Compared to the homogeneous-electricalconductivity model, a higher local residual stress can be seen in the lower right region of the inhomogeneous model.
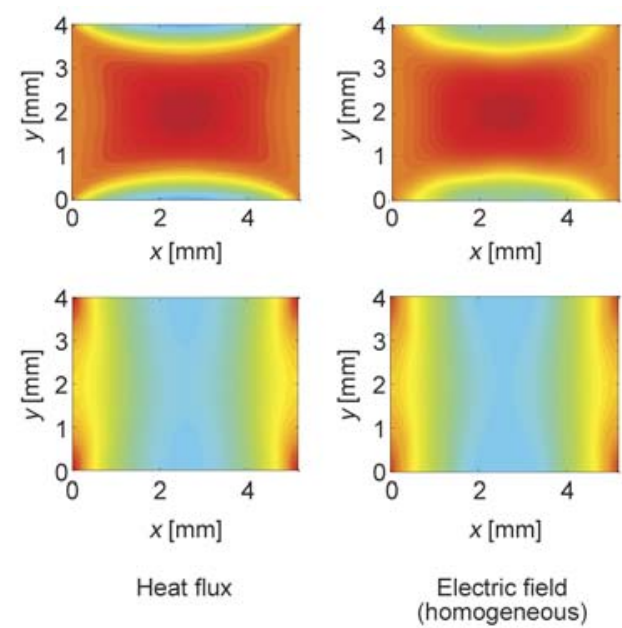

Heat flux
Figure 8 shows the residual stress in the case of double-sided heating. Similar to the case of onesided heating, the electric-field heating generally suppresses residual stress compared with the heatflux model. However, very high local residual stress is present in the lower right region of the inhomogeneous model, even compared with the heat-flux model. This is due to the very high electrical conductivity in the lower right part of the inhomogeneous model, as shown in Figure 5d, and to the large amount of heat generated in the high-electrical-conductivity region.

\section{Conclusions}

In the present study, numerical simulations were performed to evaluate the residual stress of CNTfilled resins cured under an electric field, taking into account the distribution of CNTs in the resins. The simulations were set up using the linear viscoelastic model and the unsteady-heat-transfer equation for the heat generated by Joule heating and the cure reaction. In addition, microscope images of actual CNT-filled resins were used to model the inhomogeneous electric conductivity due to CNT aggregates. The simulation results show that compared with external heating using heat flux, even though the electric field generally suppresses the residual stress, the inhomogeneous electrical conductivity due to the CNT aggregates may induce very high local residual stress. Therefore, in order to accurately determine the residual stress of CNT-filled resins, it is necessary to take into consideration the inhomogeneity of the electrical conductivity.
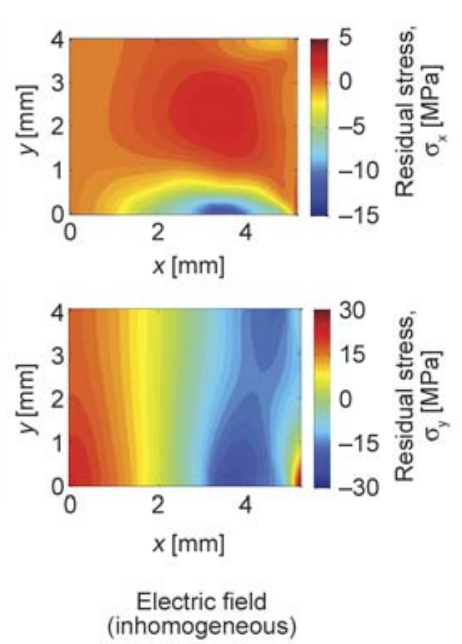

Figure 8. Cross-sectional contour plots of residual stresses $\sigma_{\mathrm{x}}$ and $\sigma_{\mathrm{y}}$ for CNT-filled resin heated from both sides of the mold after $3600 \mathrm{~s}$ of heating by heat flux and electric field 


\section{References}

[1] Plepys A. R., Farris R. J.: Evolution of residual stresses in three-dimensionally constrained epoxy resins. Polymer, 31, 1932-1936 (1990).

DOI: 10.1016/0032-3861(90)90019-U

[2] Bogetti T. A., Gillespie Jr J. W.: Process-induced stress and deformation in thick-section thermoset composite laminates. Journal of Composite Materials, 26, 626660 (1992).

DOI: $10.1177 / 002199839202600502$

[3] Thostenson E. T., Chou T-W.: Microwave and conventional curing of thick-section thermoset composite laminates: Experiment and simulation. Polymer Composites, 22, 197-212 (2001).

DOI: $10.1002 / p c .10531$

[4] Maenz S., Mühlstädt M., Jandt K. D., Bossert J.: Mechanical properties of microwave cured glass fibre epoxy composites prepared by resin transfer moulding. Journal of Composite Materials, in press (2014). DOI: $10.1177 / 0021998314557295$

[5] Papargyris D. A., Day R. J., Nesbitt A., Bakavos D.: Comparison of the mechanical and physical properties of a carbon fibre epoxy composite manufactured by resin transfer moulding using conventional and microwave heating. Composites Science and Technology, 68, 1854-1861 (2008).

DOI: $10.1016 /$ j.compscitech.2008.01.010

[6] Zhou J., Shi C., Mei B., Yuan R., Fu Z.: Research on the technology and the mechanical properties of the microwave processing of polymer. Journal of Materials Processing Technology, 137, 156-158 (2003).

DOI: 10.1016/s0924-0136(02)01082-8

[7] Tanrattanakul V., Jaroendee D.: Comparison between microwave and thermal curing of glass fiber-epoxy composites: Effect of microwave-heating cycle on mechanical properties. Journal of Applied Polymer Science, 102, 1059-1070 (2006).

DOI: 10.1002 /app. 24245

[8] Zhou S., Hawley M. C.: A study of microwave reaction rate enhancement effect in adhesive bonding of polymers and composites. Composite Structures, 61, 303-309 (2003).

DOI: $10.1016 / \mathrm{s} 0263-8223(03) 00061-8$

[9] Chen M., Siochi E. J., Ward T. C., McGrath J. E.: Basic ideas of microwave processing of polymers. Polymer Engineering and Science, 33, 1092-1109 (1993). DOI: $10.1002 /$ pen.760331703

[10] Bayerl T., Duhovic M., Mitschang P., Bhattacharyya D.: The heating of polymer composites by electromagnetic induction - A review. Composites Part A: Applied Science and Manufacturing, 57, 27-40 (2014). DOI: $10.1016 /$ j.compositesa.2013.10.024

[11] Thostenson E. T., Chou T-W.: Microwave processing: Fundamentals and applications. Composites Part A: Applied Science and Manufacturing, 30, 1055-1071 (1999). DOI: $10.1016 / \mathrm{S} 1359-835 \mathrm{X}(99) 00020-2$
[12] Higginbotham A. L., Moloney P. G., Waid M. C., Duque J. G., Kittrell C., Schmidt H. K., Stephenson J. J., Arepalli S., Yowell L. L., Tour J. M.: Carbon nanotube composite curing through absorption of microwave radiation. Composites Science and Technology, 68, 3087-3092 (2008).

DOI: 10.1016/j.compscitech.2008.07.004

[13] Rangari V. K., Bhuyan M. S., Jeelani S.: Microwave curing of CNFs/EPON-862 nanocomposites and their thermal and mechanical properties. Composites Part A: Applied Science and Manufacturing, 42, 849-858 (2011).

DOI: 10.1016/j.compositesa.2011.03.014

[14] Sung P-C., Chiu T-H., Chang S-C.: Microwave curing of carbon nanotube/epoxy adhesives. Composites Science and Technology, 104, 97-103 (2014).

DOI: 10.1016/j.compscitech.2014.09.003

[15] Liu F., Qian X., Wu X., Guo C., Lei Y., Zhang J.: The response of carbon black filled high-density polyethylene to microwave processing. Journal of Materials Processing Technology, 210, 1991-1996 (2010).

DOI: $10.1016 /$ j.jmatprotec.2010.07.014

[16] Wang G., Tan Z., Liu X., Chawda S., Koo J-S., Samuilov V., Dudley M.: Conducting MWNT/poly(vinyl acetate) composite nanofibres by electrospinning. Nanotechnology, 17, 5829-5835 (2006).

DOI: $10.1088 / 0957-4484 / 17 / 23 / 019$

[17] Reia da Costa E. F., Skordos A. A., Partridge I. K., Rezai A.: RTM processing and electrical performance of carbon nanotube modified epoxy/fibre composites. Composites Part A: Applied Science and Manufacturing, 43, 593-602 (2012).

DOI: 10.1016/j.compositesa.2011.12.019

[18] Bauhofer W., Kovacs J. Z.: A review and analysis of electrical percolation in carbon nanotube polymer composites. Composites Science and Technology, 69, 14861498 (2009).

DOI: 10.1016/j.compscitech.2008.06.018

[19] Wang L., Dang Z-M.: Carbon nanotube composites with high dielectric constant at low percolation threshold. Applied Physics Letters, 87, 042903/1-042903/3 (2005).

DOI: $10.1063 / 1.1996842$

[20] Rul S., Lefèvre-schlick F., Capria E., Laurent C., Peigney A.: Percolation of single-walled carbon nanotubes in ceramic matrix nanocomposites. Acta Materialia, 52, 1061-1067 (2004).

DOI: $10.1016 /$ j.actamat.2003.10.038

[21] Khare R., Bose S.: Carbon nanotube based composites - A review. Journal of Minerals and Materials Characterization and Engineering, 4, 31-46 (2005).

DOI: $10.4236 / \mathrm{jmmce} .2005 .41004$ 
[22] Lee S-B., Choi O., Lee W., Yi J-W., Kim B-S., Byun JH., Yoon M-K., Fong H., Thostenson E. T., Chou T-W.: Processing and characterization of multi-scale hybrid composites reinforced with nanoscale carbon reinforcements and carbon fibers. Composites Part A: Applied Science and Manufacturing, 42, 337-344 (2011).

DOI: $10.1016 /$ j.compositesa.2010.10.016

[23] Gibson R. F.: A review of recent research on mechanics of multifunctional composite materials and structures. Composite Structures, 92, 2793-2810 (2010). DOI: 10.1016/j.compstruct.2010.05.003

[24] Kobayashi S., Matsuzaki R., Todoroki A.: Multipoint cure monitoring of CFRP laminates using a flexible matrix sensor. Composites Science and Technology, 69, 378-384 (2009). DOI: $10.1016 /$ j.compscitech.2008.10.029

[25] Matsuzaki R., Kobayashi S., Todoroki A., Mizutani Y.: Control of resin flow/temperature using multifunctional interdigital electrode array film during a VaRTM process. Composites Part A: Applied Science and Manufacturing, 42, 782-793 (2011).

DOI: 10.1016/j.compositesa.2011.03.004

[26] Matsuzaki R., Kobayashi S., Todoroki A., Mizutani Y.: Full-field monitoring of resin flow using an area-sensor array in a VaRTM process. Composites Part A: Applied Science and Manufacturing, 42, 550-559 (2011).

DOI: 10.1016/j.compositesa.2011.01.014

[27] Matsuzaki R., Kobayashi S., Todoroki A., Mizutani Y.: Cross-sectional monitoring of resin impregnation using an area-sensor array in an RTM process. Composites Part A: Applied Science and Manufacturing, 43, 695702 (2012).

DOI: 10.1016/j.compositesa.2011.12.024

[28] Hatori S., Matsuzaki R., Todoroki A.: Cost-effective open microwave heating of polymer resin using interdigital electrode array film and dispersed carbon nanotubes. Composites Science and Technology, 92, 9-15 (2014).

DOI: $10.1016 /$ j.compscitech.2013.11.029
[29] Bykov Y. V., Rybakov K. I., Semenov V. E.: High-temperature microwave processing of materials. Journal of Physics D: Applied Physics, 34, R55-R75 (2001).

DOI: $10.1088 / 0022-3727 / 34 / 13 / 201$

[30] Fotiou I., Baltopoulos A., Vavouliotis A., Kostopoulos V.: Microwave curing of epoxy polymers resinforced with carbon nanotubes. Journal of Applied Polymer Science, 129, 2754-2764 (2013).

DOI: 10.1002/app.39003

[31] Mas B., Fernández-Blázquez J. P., Duval J., Bunyan H., Vilatela J. J.: Thermoset curing through joule heating of nanocarbons for composite manufacture, repair and soldering. Carbon, 63, 523-529 (2013).

DOI: $10.1016 /$ j.carbon.2013.07.029

[32] Li J., Ma P. C., Chow W. S., To C. K., Tang B. Z., Kim J-K.: Correlations between percolation threshold, dispersion state, and aspect ratio of carbon nanotubes. Advanced Functional Materials, 17, 3207-3215 (2007). DOI: $10.1002 / \mathrm{adfm} .200700065$

[33] Park H. C., Lee S. W.: Cure simulation of thick composite structures using the finite element method. Journal of Composite Materials, 35, 188-201 (2001). DOI: $10.1177 / 002199801772662217$

[34] Ruiz E., Trochu F.: Numerical analysis of cure temperature and internal stresses in thin and thick RTM parts. Composites Part A: Applied Science and Manufacturing, 36, 806-826 (2005). DOI: $10.1016 /$ j.compositesa.2004.10.021

[35] Kim Y. K., White S. R.: Stress relaxation behavior of 3501-6 epoxy resin during cure. Polymer Engineering and Science, 36, 2852-2862 (1996).

DOI: $10.1002 /$ pen. 10686

[36] Rouison D., Sain M., Couturier M.: Resin transfer molding of natural fiber reinforced composites: Cure simulation. Composites Science and Technology, 64, 629644 (2004).

DOI: $10.1016 /$ j.compscitech.2003.06.001 